Joaquin Fermandois, La revolución inconclusa: La izquierda chilena y el gobierno de la Unidad Popular (Centro de Estudios Públicos, 2013, Santiago).

\title{
¿DEMOCRACIA POPULAR EN CHILE?
}

\section{Sofía Correa Sutil}

Universidad de Chile

\begin{abstract}
E 1 gobierno de la Unidad Popular y su derrumbe con el golpe de
- Estado de septiembre del 73 ha sido, desde muy temprano, objeto de estudio desde diversas disciplinas sociales tanto en Chile como por académicos extranjeros. Recientemente el Centro de Estudios Públicos ha sacado a luz un voluminoso libro del historiador Joaquín Fermandois: La revolución inconclusa. La izquierda chilena y el gobierno de la Unidad
\end{abstract} Popular. Se trata de un trabajo apoyado desde sus inicios por el CEP. Tal como lo relata el autor en el prólogo, la obra nace de conversaciones sostenidas hace ya algunos años con Arturo Fontaine, su entonces director, cuyo entusiasmo lo llevó a incentivar este trabajo, lo que le permitió al autor concentrarse durante tres años en la investigación y escritura del libro, apoyado por un grupo de colaboradores-ayudantes con los cuales abordó la revisión sistemática de buena parte de la bibliografía producida sobre el período, de fuentes documentales, prensa y archivos, los que le resultaron particularmente útiles, especialmente, a juicio del autor, aquellos que contenían la documentación oficial de la República Democrática Alemana. El resultado ha sido un libro de más de 850 páginas, con 28 capítulos y una extensa bibliografía e índices analíticos. Una producción voluminosa así como ambiciosa.

Sofía Correa Sutil. Historiadora. DPhil Oxford University. Académica de la Facultad de Derecho de la Universidad de Chile. Dirección electrónica: scorrea@ derecho.uchile.cl. 
En efecto, el autor ha decidido, no queda claro por qué, iniciar el estudio del período de la Unidad Popular a partir de la Independencia y la historia política republicana de principios del siglo XIX, trabajados en los primeros y más débiles capítulos del libro ${ }^{1}$. No obstante, este comienzo nos permite percibir tempranamente la visión dicotómica del autor en un relato donde los matices históricos e historiográficos han desaparecido para mostrarnos un constante choque entre dos fuerzas antagónicas a lo largo de la historia de Chile. Su afirmación de que desde los primeros tiempos de la república existe una derecha y una izquierda en permanente conflicto no es sostenible, y de hecho Fermandois no se hace cargo de la discusión historiográfica sobre los orígenes de estas fuerzas en la política chilena, así como tampoco trata la historia de los partidos que las representan $^{2}$.

Estos primeros capítulos del libro tienen un tono didáctico, escolar, tajante y taxativo, acompañado de un lenguaje llamativamente coloquial, reflejado en expresiones tales como: “¿Qué vino primero: el huevo o la

${ }^{1}$ Fermandois no explica por qué habría que remontarse a los inicios de la República para entender a la izquierda chilena y al gobierno de la Unidad Popular. Tampoco recoge —ni para discutir u objetar ni para confirmar - las tesis de quienes han establecido continuidades desde la Independencia hasta la Unidad Popular. Por ejemplo, Gabriel Salazar ha creado una especie de morfología de los procesos políticos chilenos desde la Independencia a la actualidad, según la cual se enfrentan permanentemente los productores con los mercaderes, los cuales, en cuanto clase político-militar, continuamente reprimirán los intentos del pueblo - productorpor ejercer efectivamente su soberanía. Por su parte, Alfredo Jocelyn-Holt en La Independencia de Chile sostiene que el republicanismo adoptado desde los inicios del proceso de independencia si bien le permite a la elite decimonónica controlar el poder político durante más de un siglo, a la vez tiene tales proyecciones que es este mismo republicanismo decimonónico el que, dando cabida a un proceso revolucionario que comienza en la década de 1960, permite que Allende llegue a la Presidencia. Gonzalo Vial argumentó que para comprender el golpe de Estado del 73 había que remontarse hasta mediados del siglo XIX cuando se expresa el primer quiebre del consenso doctrinario católico, pues sería en la ruptura de los consensos donde radicaría el quiebre de la sociedad chilena en los 70 .

${ }^{2}$ Son muchos los trabajos que se han publicado sobre la historia de los partidos políticos de la izquierda chilena (Ramírez Necochea, Jobet, Drake, Faúndez, Moulian, Angell, Varas, etcétera). En cuanto a la derecha chilena, en mi libro Con las riendas del poder me hago cargo de una extensa discusión teórica extranjera sobre qué es ser de derecha para concluir que sólo hay derecha en Chile a partir de la década de 1930 . 
gallina?"3, o bien: "Como en Condorito, esto exige una explicación"4. Aunque esta estrategia discursiva está menos presente en los capítulos centrales del libro, en ellos se da cabida a caracterizaciones ampliamente conocidas, como por ejemplo la de Chile como país rural antes de la reforma agraria (capítulo 14). En consecuencia cabe preguntarse a quién está destinada esta obra, quién es el potencial lector al que el autor le habla en las casi 800 páginas de texto. No queda claro, y probablemente habría que diferenciar partes distintivas del libro: los inicios con sus generalizaciones históricas; y el relato dramático de los acontecimientos mes a mes durante el gobierno de la Unidad Popular, que es cuando el libro adquiere potencia narrativa y captura con mayor intensidad el interés del lector.

No es fácil historiar el propio presente. Fermandois ha optado por generar en su escritura un distanciamiento entre su propia experiencia y los tiempos que relata, quizás buscando dar cuenta del período con una mayor objetividad. No obstante es imposible negarse a la presencia de la subjetividad del historiador en cualquier obra histórica y con mayor razón si en ella se tratan tiempos contemporáneos cuya persistencia es aún vívida. Es mejor hacerla evidente, que es, por lo demás, lo que hacen Hobsbawm y Judt cuando escriben sobre una historia, la del siglo XX o de la postguerra en cada caso, que han vivido intensamente ${ }^{5}$. Por eso, en los capítulos medula-

3 Joaquín Fermandois, La revolución inconclusa. La izquierda chilena y el gobierno de la Unidad Popular (Santiago: Centro de Estudios Públicos, 2013), 41.

${ }^{4}$ Ibídem, 89.

${ }^{5}$ Dice Eric Hobsbawm en la introducción de su libro Historia del siglo $X X$, 1914-1991: "Mi propósito es comprender y explicar por qué los acontecimientos ocurrieron de esa forma y qué nexo existe entre ellos. Para cualquier persona de mi edad que ha vivido durante todo o la mayor parte del siglo XX, esta tarea tiene también, inevitablemente, una dimensión autobiográfica, ya que hablamos y nos explayamos sobre nuestros recuerdos (y también los corregimos). Hablamos como hombres y mujeres de un tiempo y un lugar concretos, que han participado en su historia en formas diversas. Y hablamos, también, como actores que han intervenido en sus dramas - por insignificante que haya sido nuestro papel—, como observadores de nuestra época y como individuos cuyas opiniones acerca del siglo han sido formadas por los que consideramos acontecimientos cruciales del mismo. Somos parte de este siglo, que es parte de nosotros. [...] Para el autor del presente libro, el 30 de enero de 1933 no es una fecha arbitraria en la que Hitler accedió al cargo de canciller de Alemania, sino una tarde de invierno en Berlín en que un joven de quince años, acompañado de su hermana pequeña, recorría el camino que le conducía desde su escuela, en Wilmersdorf, hacia su casa, en Halensee, y que en un punto cualquiera del trayecto leyó el titular de la noticia. Todavía lo veo como en un sueño". (Barcelona: Crítica, 1995, 13-14) 
res del libro, que tratan sobre el gobierno de la Unidad Popular siguiendo su desarrollo año a año, mes a mes, uno se pregunta constantemente cuáles fueron las experiencias, cuáles los recuerdos personales y las emociones del autor sobre esa época tan convulsionada que él está trayendo de vuelta al lector, impulsándole a su vez a convocar los propios fantasmas que hibernan en el recuerdo que cada cual tiene de aquellos años emocionalmente tan presentes todavía. Habrá, por cierto, lectores que no habían siquiera nacido para aquel entonces, pero aun ellos están llenos de estas presencias fantasmales. De allí, supongo, la necesidad de escribir este libro que busca darles inteligibilidad, precisamente en un tiempo en el que se han revitalizado unos ideales revolucionarios acompañados de una nostalgia de izquierdas por el período de la Unidad Popular, particularmente notorio con ocasión de la remembranza de los 40 años del golpe de Estado en 2013, año en que se publica este libro.

He ahí entonces al autor que ha decidido ocultar del lector su experiencia vital de aquellos años que va a historiar. Y sin embargo su subjetividad se vuelve omnipresente, pero de una manera oblicua, como cuando mezcla datos duros con conjeturas no explicitadas como tales, de tal modo que éstas podrían leerse como información irrefutable, que es lo que ocurre, por ejemplo, cuando se refiere a la opinión pública en el contexto de la división del PDC a fines de la década de 1960, afirmando (las cursivas en esta cita y las siguientes son mías):

Nada de esto impidió que la figura de Eduardo Frei siguiera concitando admiración. No sería demasiado aventurado afirmar que, si hubiera existido el tipo de encuesta que sería común cuatro décadas después, su tasa de aprobación podría fijarse en alrededor del 50\%. La Democracia Cristiana bajó bastante en las elecciones de 1969 , alcanzando un $29 \%$ de los votos. Esta votación, como se explicará más largamente después, sería bastante estable hasta el año 1973 y en su abrumadora mayoría obedecía a una identificación con la idea y con el prestigio político de Eduardo Frei. ${ }^{6}$

Ocurre algo semejante en otras ocasiones, en las que especula con cifras y porcentajes sin ningún respaldo documental, referidas también a las opiniones de la ciudadanía, esta vez en tiempos del gobierno de la Unidad Popular; así, por ejemplo sostiene que:

\footnotetext{
${ }^{6}$ Fermandois, La revolución inconclusa, 153.
} 
Es cierto que, preguntando quizás a los chilenos si les importaba mucho que estas empresas fueran propiedad del Estado (o de los "trabajadores"), no es improbable que la mitad o más hubiera aprobado un traspaso de propiedad, aunque no necesariamente esto implicase la expropiación sin compensación. Entre noviembre de 1970 y mediados de 1971, pensamos que en general una mayoría de los chilenos estaba todavía en este estado de ánimo, pero a la vez, tras el relajo inicial, iba creciendo en la mitad de los chilenos la alarma por la situación que se podía crear. ${ }^{7}$

Esta manera de insertar suposiciones tal como si fuesen información segura resulta en otras ocasiones mucho menos inocente, como cuando, por ejemplo, se refiere a los días siguientes a la elección presidencial de 1970:

Es posible que Eduardo Frei hubiese estado en una especie de depresión anímica. Algo de esto traslucía en las fotos de la época y en su semblante. Le parecía tan increible lo que había sucedido que no es impensable, con estas señales, que su actitud pasiva se debiera a que en lo profundo de sus sentimientos deseaba ser depuesto por las fuerzas armadas. En Chile estaba el antecedente de 1924 que desembocó, en primera instancia, en el regreso triunfal de Arturo Alessandri. En segunda instancia, significó entregarle el poder a un tercero que rápidamente aferró la oportunidad en su puño, Carlos Ibáñez. Todas estas cosas deben de haber pasado por su mente, tanto como por la conciencia de que violentar el espíritu de la Constitución era ir contra una doctrina sostenida por él desde siempre. La situación en el gabinete tenía otra cara. Según Korry ${ }^{8}$, Frei había dicho a algunos jefes militares que la situación le parecía terrible [aquí Fermandois cita archivo norteamericano]. Si no fue así, en todo caso, estos tienen que haber captado el ambiente de fin de mundo y de pesimismo más absoluto que se daba en las principales cabezas del Gobierno. ${ }^{9}$

Esta forma de historiar intercalando elucubraciones caprichosas y sesgadas con información obtenida de fuentes indubitables, como los archivos diplomáticos, que va marcando las tintas de la lectura, es por cierto muy perturbadora. Así también sorprende que en múltiples ocasiones Fermandois plantee afirmaciones muy relevantes sin que dé cuenta de su fuente de

\footnotetext{
${ }^{7}$ Ibídem, 391.

${ }^{8}$ Edward Korry era el embajador de los Estados Unidos en Chile en 1970.

${ }^{9}$ Fermandois, La revolución inconclusa, 340.
} 
información. Ocurre, por ejemplo, cuando el autor da a entender que Frei habría actuado en conjunto con los militares que estaban organizando el golpe de Estado en 1973:

Los generales Sergio Arellano, Oscar Bonilla, Nicanor Díaz, los almirantes José Toribio Merino y Patricio Carvajal no operaban en un vacio ajeno al mundo civil. Ahora todas las fuerzas que pretendían terminar con la Unidad Popular querían establecer una prueba de fuego, ya que estaban convencidos [sic] de que sería la última oportunidad. ${ }^{10}$

$$
[\ldots]
$$

Era en esta atmósfera en la cual las fuerzas armadas parecían converger más con la oposición que con el Gobierno, aunque este último prefería no reconocerlo, pues confiaba en que al final el alto mando del Ejército era su mejor garantía. Hasta donde es posible darse cuenta, para los oficiales era indiferente si se trataba de líderes de la derecha o de la Democracia Cristiana. De todos llegaban recados convocándolos a que hicieran algo. En particular, Eduardo Frei seguía muy relacionado con sus ex edecanes, los ahora generales Oscar Bonilla y Sergio Arellano, además del comandante de la Armada Eduardo Angulo Budge. ${ }^{11}$

También cuando se refiere al acuartelamiento del general Viaux en el Regimiento Tacna en octubre de 1969:

Toda la evidencia indica que no hubo ningún intento de golpe $e^{12}$. Fue otra "toma" para promocionar, de manera muy convincente eso sí, sus propias demandas. Después de la toma comenzó una negociación entre las partes, la que culminó con un acuerdo que en lo sustancial recogía las demandas por salarios y equipamientos. En este sentido, el Gobierno entregó la oreja de manera rotunda. Dos fenómenos, sin embargo, acompañaron esta realidad. Primero, que el Tacna fue rodeado por otras unidades del Ejército

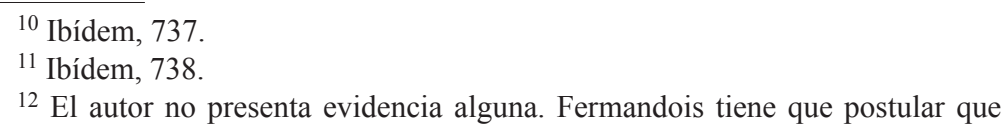
no había intento de golpe de Estado en la insubordinación de Viaux porque su interpretación sobre la actuación de los militares durante el gobierno de la Unidad Popular se sostiene en que las fuerzas armadas fueron efectivamente no deliberantes y apolíticas desde fines de 1932 hasta el mismo año 73, a lo más el 72. 
y de otras ramas, pero que no tenían la más mínima intención de emplear la fuerza. Cumplieron con las órdenes de trasladarse hasta allí, pero compartían sin ninguna duda la posición de los alzados $^{13}$.

Esta ausencia de las fuentes de información respecto a las actuaciones de las fuerzas armadas ocurre con mayor intensidad cuando el autor va conduciendo al lector hacia un creciente escalamiento del conflicto durante el año 73, e indicando señales de la planificación del golpe de Estado, haciendo presente las acciones que van ocurriendo en las distintas ramas de las fuerzas armadas. Como, por ejemplo, al tratar la llegada a Santiago de los mineros del cobre en paro en junio del 73 :

La situación se veía más tensa, además, por la gran cantidad de sabotajes que comenzaron a producirse, especialmente en comunicaciones, caminos y en torres de alta tensión. Es de presumir que ya estaban en acción grupos de los servicios de inteligencia de las tres ramas, que comenzaban a participar en un esfuerzo por precipitar las condiciones de una intervención militar. ${ }^{14}$

De modo que nos vamos enterando de cómo se va gestando el golpe de Estado al interior del mundo militar, sin saber si Fermandois tiene conocimiento directo de fuentes militares o ha recogido testimonios orales o de qué otra forma pudo llegar al conocimiento de cuestiones tan reveladoras como las siguientes:

En realidad, a mediados de 1973 se podría decir que una inmensa cantidad de oficiales y hasta de suboficiales estaba conversando, deliberando y a veces efectuando planes de "hacer algo" contra la Unidad Popular. Esto se daba especialmente en los oficiales intermedios: capitanes, mayores y tenientes coroneles, capitanes de corbeta y capitanes de fragata. La mediana graduación explica en parte el alzamiento del llamado Tancazo. [...]

$\mathrm{Al}$ menos desde los días de la ENU de fines de marzo y comienzos de abril de 1973, los oficiales intermedios comenzaron a hablar abiertamente entre ellos y a veces con sus jefes. [...] Surgía todo tipo de planes disparatados de acción. Como hemos visto, es probable que ya muchos oficiales y otro personal de algunas ramas colaboraran con los métodos de acción directa de algunos

\footnotetext{
${ }^{13}$ Ibídem, 179.

${ }^{14}$ Ibídem, 664-665.
} 
grupos de oposición. A veces esto era simple terrorismo, aunque todavía sin muertos. A veces los oficiales jóvenes conminaban a sus jefes a la acción. Estos preferían aguardar con prudencia o no comprometerse en los hechos y no tenían nada claro qué se debería hacer.

El grupo que tenía más relación con los oficiales, que estaban siendo cada día más rebeldes, era Patria y Libertad. Operaba muy de cerca con núcleos de estos oficiales. ${ }^{15}$

En cuanto a las tesis que sostienen esta obra, es notorio que Joaquín Fermandois logra dar coherencia a lo largo de todo el libro a su interpretación sobre el gobierno de la Unidad Popular, y por tanto sobre el golpe de Estado. Llama la atención sin embargo que ésta se desenvuelva página tras página sin hacer nunca mención a las numerosas, diversas y divergentes interpretaciones que se han planteado sobre este problema histórico ${ }^{16}$. En ese sentido, es como si el libro se escribiera en una suerte de vacío historiográfico, a pesar de la extensa bibliografía consignada en las páginas finales y citada numerosas veces en este libro refiriendo a la información que ella contiene ${ }^{17}$.

Le preocupa al autor que en la opinión pública y en la academia europea así como también norteamericana, prevalezca una opinión positiva tan-

${ }^{15}$ Ibídem, 661. Para confrontar otros ejemplos de información sobre las fuerzas armadas sin referencias sobre las fuentes que la respalden, véanse también las páginas 575-576, 652-661, 665-668, 697-705, 758, 761-762.

16 Por ejemplo: Arturo Valenzuela, El quiebre de la democracia en Chile (primera edición en castellano: Flacso, 1978); Mario Góngora, Ensayo histórico sobre la noción de Estado en Chile en los siglos XIX y XX (Ediciones La Ciudad, 1981); Gonzalo Vial Correa, "Decadencia, consensos y unidad nacional en 1973" en Dimensión Histórica de Chile N¹, 1984; Manuel Antonio Garretón y Tomás Moulian, La Unidad Popular y el conflicto político en Chile (Lom, 1993); James Whelan, Desde las cenizas: vida muerte y transfiguración de la democracia en Chile 1833-1988 (Zig-Zag, 1993); Alfredo Jocelyn-Holt, El Chile perplejo. Del avanzar sin transar al transar sin parar (Planeta, 1998); Gabriel Salazar y Julio Pinto, Historia contemporánea de Chile (Lom, 1999); Sofía Correa et al., Historia del siglo XX chileno. Balance paradojal (Sudamericana, 2001); Luis Corvalán Márquez, Del anticapitalismo al neoliberalismo en Chile (Sudamericana, 2001); Tomás Moulian, Fracturas. De Pedro Aguirre Cerda a Salvador Allende (Lom, 2006), etcétera.

${ }^{17}$ Aunque no siempre se cita cuando corresponde a los autores referidos en la bibliografía, es particularmente notorio cuando el autor especula sobre el pensamiento de Carlos Altamirano en las páginas 289, 297 y 746 sin referirse a los dos principales libros de entrevistas a Altamirano, el de Patricia Politzer (1990) y el de Gabriel Salazar (2010), aunque sí los cita en las páginas 759, 760 y 763. 
to del gobierno de la Unidad Popular como de Salvador Allende, sostenida en la convicción errónea, a su juicio, de que se trataría de una experiencia socialdemócrata que buscaba hacer profundos cambios para terminar con las injusticias sociales preservando el sistema político democrático. Fermandois se propone en este libro demostrar el error de esta visión. Para ello, caracteriza a las fuerzas de izquierda y a Allende como actores centrales de esta historia en cuanto habrían precipitado la crisis política llevando al país a un callejón cuya única salida habría quedado en manos de las fuerzas armadas.

Si bien el autor afirma, como ya veíamos, que existe izquierda en Chile desde tiempos de la Independencia, también constata que a partir de la década de 1930 la izquierda chilena será marxista, y con ello la política chilena se redefinirá en la polaridad marxismo-antimarxismo, la que habría sucedido a la "antigua polaridad liberal-conservadora del siglo XIX"18. Por tanto - sostiene - la izquierda chilena, en todas sus vertientes partidarias, tendrá como meta la consecución de una sociedad socialista a semejanza de las que existieran en la Unión Soviética y luego en la República Democrática Alemana (la RDA comunista) y en la Cuba de Castro, las tres experiencias políticas que más influyeron en la izquierda chilena a juicio de Fermandois. De allí que cuando en Chile la izquierda hablaba de democracia no estaría entendiendo por ello la democracia liberal con Estado de derecho, como se la comprende en el mundo occidental, sino que estaría pensando en un régimen totalitario como el de las repúblicas democráticas de Europa del Este bajo el control soviético, concluye el autor.

Por lo mismo, la izquierda habría entendido la Constitución — particularmente la de 1925 - como la concreción de las demandas del pueblo exigidas en una larga lucha política encarnada y conducida por ella misma, y por tanto, la Constitución no podría ser concebida o invocada como contención a dichas demandas. Por cierto, hace notar Fermandois, se trata de una concepción de la Constitución, y de la legalidad en general, que no se corresponde con el pensamiento político occidental. De allí que las fuerzas

${ }^{18}$ Fermandois, La revolución inconclusa, 74. La polaridad marxismo-antimarxismo que el autor instala en los años 30 le lleva a sostener que: "Incluso se podría decir, con su cuota de exageración, que en Chile la Guerra Fría comenzó antes que la Guerra Fría del sistema internacional" (186). Tan anacrónica afirmación no permite dar cuenta de las alianzas multipartidistas en la conducción del Estado en la década de 1940, que contó con participación en el gobierno desde el Partido Liberal al Partido Comunista, a veces en un mismo gabinete. 
de izquierda durante el gobierno de la Unidad Popular, si bien respetaron la letra de la Constitución, habrían vulnerado su espíritu, y en cuanto a la legalidad, recurrirían a los resquicios legales para torcerla a su favor. Esta postura política, ya decíamos, sería común a todas las fuerzas de izquierda, las cuales habrían utilizado el sistema democrático liberal prevaleciente en Chile para desde allí intentar destruirlo con el propósito de establecer un nuevo orden socialista marxista. En este contexto, la excepcionalidad de Chile que postula Fermandois consistiría en que el país tenía una sólida institucionalidad política democrática previa a la movilización de las fuerzas de izquierda, que es lo que explicaría por qué éstas tuvieron que adoptar la estrategia de funcionar dentro del sistema, dado que era la única manera en que podían "alcanzar el poder", no obstante lo cual no renunciaron a utilizar medidas de fuerza para conseguir sus objetivos, como "los resquicios legales, las 'tomas', la movilización en general, la preparación clandestina de sus cuadros y la organización de grupos armados"19.

Es a partir de la lógica derivación de sus postulados marxistas que Fermandois caracteriza a la izquierda chilena como una entidad homogénea y antisistémica. Dado que la mirada del autor se sitúa en el plano de los planteamientos políticos soslayando las actuaciones históricas, no le interesa detenerse a analizar el comportamiento de estas fuerzas de izquierda dentro del sistema político chileno, donde sí aparecen matices, conflictos entre ellas tensionados en gran medida por sus referentes internacionales - el PS, por ejemplo, era muy cercano a los Estados Unidos en los años $40^{20}$ - y cuando es evidente su constante participación en el sistema democrático, ya sea a través de la representación en el Congreso Nacional, como en el ejecutivo, con ministros de Estado y altos funcionarios. Esa historia partidista llena de matices no es de interés para Fermandois, en gran medida porque no le permite asentar su visión dicotómica de una historia de confrontación entre dos polos, en la cual no hay cabida posible a la negociación y al acuerdo, donde en el fondo la política es guerra. Por lo antedicho, a pesar de la existencia de dos partidos de izquierda con una larga historia de rivalidades entre ellos, a juicio del autor las diferencias entre socialistas y comunistas no serían significativas, pues ambos tendrían en

${ }^{19}$ Ibídem, 240.

${ }^{20}$ Tanto así que la mitad de los parlamentarios del Partido Socialista votaron a favor de la proscripción del Partido Comunista al aprobar la Ley de Defensa Permanente de la Democracia en 1948. 
común el objetivo final de llegar a establecer en Chile una dictadura marxista a la que llamaban democracia popular. Por lo mismo, cuando relata la historia del gobierno de la Unidad Popular, Fermandois no le otorga importancia a las tensiones entre ambos partidos (y los pequeños partidos que se posicionan en torno a éstos).

En cuanto al otro sujeto de esta historia, Salvador Allende, éste no sería el Presidente socialdemócrata que algunos quieren hacer creer. Por el contrario, siendo un socialista marxista, y muy cercano al Partido Comunista, desde sus primeras incursiones en política habría buscado, a juicio de Fermandois, llevar a Chile hacia el modelo marxista totalitario, aunque utilizando la "legalidad burguesa", lo que a juicio del autor sería comparable "en términos abstractos" a "lo que hicieron los nazis en Alemania en 1933"21. Es más, asegura, para Allende, fuese como senador o luego como Presidente de la República, todas las formas de lucha, incluida la lucha armada, eran legítimas. "Estaba seducido por los revolucionarios del estilo castrista" 22 , sostiene Fermandois. Por eso, una vez instalado en La Moneda, se vinculó estrechamente con Fidel Castro, tuvo cercanía con el MIR que apostaba a la lucha armada incluso durante los años del gobierno de la Unidad Popular, convivió con los grupos paramilitares del Partido Socialista, toleró las tomas y las organizaciones del poder popular, y confió su seguridad personal al GAP 23 , "un cuerpo paramilitar con instrucción de guerra" incrustado en "el corazón geográfico del Estado", en la Presidencia de la República. Por lo demás, el papel que habría desempeñado Allende en aquellos tres años de gobierno habría sido más bien el de mediador de las diferencias al interior de la Unidad Popular — entre los partidos, la CUT y el MIR que fueron "los verdaderos actores"-; Allende habría sido el "corazón simbólico de todo el gobierno y de la Unidad Popular", pero en ningún caso sería el líder carismático de la revolución marxista, sostiene Fermandois ${ }^{24}$.

${ }^{21}$ Fermandois, La revolución inconclusa, 232.

22 Ibídem, 232.

${ }^{23}$ GAP: Grupo de Amigos Personales, guardia armada formada por civiles, militantes de izquierda, que resguardaba la seguridad presidencial durante el gobierno de Allende. Véase Cristián Pérez I., "Salvador Allende, apuntes sobre su dispositivo de seguridad: El Grupo de Amigos Personales (GAP)", en Estudios Públicos $79,2000$.

${ }^{24}$ Fermandois, La revolución inconclusa, 368-369 y 482-485. 
Por lo tanto, la historia del gobierno de la Unidad Popular se podría sintetizar, por una parte, en el intento de establecer en Chile una dictadura marxista, utilizando para este fin el sistema político democrático consolidado en el país, y, por otra parte, en el rechazo y resistencia a este intento, activado por una oposición que constituía al menos la mitad de la sociedad chilena. Se trataría de un enfrentamiento político entre dos mitades del país, una "guerra civil política", concepto central acuñado por Fermandois para dar cuenta de la historia del gobierno de la Unidad Popular, y que define como "un estado anímico de guerra civil que se da en el cuerpo político" 25 . A pesar de no tratarse de una guerra civil propiamente tal, no se descartó en ella el uso de métodos violentos de confrontación armada por parte de los civiles, iniciado primeramente por parte del MIR y replicado en seguida por la organización paramilitar de derecha Patria y Libertad, argumenta Fermandois.

El autor descarta de plano que en esta historia tenga relevancia alguna la intervención extranjera. Si bien reconoce que la hubo, ésta no habría sido significativa en el desarrollo y desenlace de los acontecimientos en la medida en que éstos habrían respondido únicamente a las acciones de las fuerzas políticas chilenas. Prueba de ello sería que el intento de evitar que asumiera Allende por parte del gobierno de Nixon fracasó. Además, la intervención extranjera se habría dado en iguales condiciones respecto a los dos bandos en pugna. Por ejemplo, si los Estados Unidos financiaron la prensa de oposición, la RDA y la URSS enviaron maquinarias para la prensa de izquierda; y si Estados Unidos hizo aportes a las campañas presidenciales chilenas, también lo hicieron los países del bloque soviético, argumenta ${ }^{26}$. Así, las potencias interventoras se neutralizan entre sí y la historia corre sólo por carriles locales, es decir, nacionales, a la vez que el conflicto se presenta siempre entre dos fuerzas de igual magnitud y capacidad de lucha.

Fermandois sostiene que la crisis política chilena tiene un origen muy preciso: el triunfo de Salvador Allende en la elección presidencial de

${ }^{25}$ Ibídem, 584 .

${ }^{26}$ No convence el argumento de que la intervención en Chile de las dos potencias en pugna durante la Guerra Fría hubiese sido de la misma magnitud. Véase Tanya Harmer, Allende's Chile \& the Interamerican Cold War (The University of North Carolina Press, 2011). 
$1970^{27}$, es decir la crisis se desencadenaría a causa del control del gobierno por las fuerzas marxistas, a raíz de lo cual el país se divide en dos mitades que se enfrentan entre sí. En efecto, en el primer año del gobierno de izquierda, en el cual la sociedad está a la expectativa de los sucesos y en el que la política económica logra muy buenos índices, la Unidad Popular logra aumentar su votación desde un tercio del electorado al 50\%. Esto lleva a que la oposición tenga que coordinar esfuerzos, especialmente después del asesinato de Pérez Zujovic en junio del 71, lo que va produciendo una alianza entre quienes hasta entonces eran enemigos políticos: la Democracia Cristiana y la derecha, quienes van a ir concretando su entendimiento a través de acuerdos electorales desde inicios del año 72.

Así fue como el país quedó dividido en dos mitades confrontadas entre sí, las cuales desde el Paro de Octubre de 1972 hasta el 11 de septiembre de 1973 se enfrentarán en una "guerra civil política", en medio de una crisis multidimensional. El relato de los acontecimientos va entonces trasmitiendo la vivencia de la tensión propia de una situación caracterizada como bélica, como cuando estando cerca del Paro de Octubre el autor constata: "Los frentes estaban armados y animados tal cual en julio de 1914. Una chispa encendería el fuego"28. A comienzos de 1973, con la consigna de la izquierda de avanzar sin transar, "las reglas del juego del sistema, el espíritu constitucional, se habían convertido en polvo", y "solo la actitud más rebelde podría detener un proyecto totalitario", concluye el autor ${ }^{29}$. En efecto, ese mismo año 73, después de las elecciones parlamentarias de mar-

27 Ya decíamos, Fermandois prescinde de la discusión historiográfica en este libro. Por lo tanto, no debate con las numerosas interpretaciones sobre la crisis política chilena que son contradictorias con la suya. Así, para Arturo Valenzuela la crisis chilena tiene sus orígenes en la ocupación del centro político por la Democracia Cristiana, partido que postulaba el camino propio impuesto sin negociaciones, sin acuerdos. Tomás Moulian, en la misma línea, desarrolló la idea de la Democracia Cristiana como centro centrífugo, que expulsa a las otras fuerzas políticas hacia una radicalización. Mario Góngora con su noción de las planificaciones globales también remontó la crisis al gobierno de la Democracia Cristiana, primera experiencia política que caracteriza como de planificación global. Gonzalo Vial va más atrás históricamente adjudicándole la causa a la ruptura del consenso en la sociedad chilena fruto de los procesos de laicización. Alfredo Jocelyn-Holt centra su interpretación en la híper-movilización social provocada por la DC e intensificada a partir de 1967. Gabriel Salazar ve en el golpe de Estado de 1973 la reiterada respuesta de la "clase política-militar" a los intentos del pueblo de ejercer su soberanía.

${ }^{28}$ Fermandois, La revolución inconclusa, 565.

${ }^{29}$ Ibídem, 602. 
zo en las que la Unidad Popular obtuvo más del $40 \%$ de los votos, los partidos de izquierda se prepararon "para una batalla, en general política, pero que algunos la empezaron a diseñar como militar" y, agrega Fermandois: "Las partes avanzaban tomando posición, lo que no hacía más que dividir cada día más a Chile en dos bandos irreconciliables entre sí” ${ }^{\text {'30 }}$.

La "guerra civil política" se dio en todos los planos e involucró a la sociedad completa, a la vez que impactó la vida cotidiana de todos sus habitantes. Las fuerzas armadas no podían mantenerse al margen, si además eran cortejadas por el gobierno y por la oposición. Serían uno y otro bando en el que estaba dividido el país los que convocaran a las fuerzas armadas a dirimir el conflicto político cada día más profundo. De modo que si el grupo paramilitar Patria y Libertad tuvo vinculaciones con "oficiales jóvenes" éstas fueron "de una manera poco organizada, de empatías más o menos espontáneas" que en todo caso "eran un complemento y una oposición a las que el MIR había desarrollado con oficiales y sobre todo con personal de tropas en el Ejército y, como bien sabemos, entre la marinería de la Armada", sostiene Fermandois. Más aún, asegura: "Existía la penetración orgánica de los principales partidos marxistas al interior de las fuerzas armadas, en especial entre suboficiales y personal que en la jerga se llama "clases""31.

Concretamente, la guerra civil política llegaba a los uniformados - a los altos mandos y a los oficiales - a través de sus familias, las que, como todos los chilenos, participaron de ésta, argumenta Fermandois. "El lenguaje de la política ingresó en buena medida a los cuarteles por la vía de los hogares, en especial a través de esposas e hijas de muchos oficiales que empezaban a participar en actividades de base de oposición"32. Es que, si bien los dos bandos en pugna buscaron resolver el empate apelando a las fuerzas armadas, éstas se fueron situando en contra del gobierno de la Unidad Popular, dado que su "inclinación 'normal' era sentirse parte de un mundo occidental al cual Chile debía lealtad"33. Dicho de otra manera: "Junto con la polarización del país, comenzó a fortalecerse esa ley de probabilidades

${ }^{30}$ Ibídem, 619.

${ }^{31}$ Ibídem, 573. Ya lo decíamos, cuando aporta información tan relevante sobre las fuerzas armadas Fermandois no da cuenta de sus fuentes de información.

${ }^{32}$ Ibídem, 704.

${ }^{33}$ Ibídem, 656. 
que hacía que los oficiales tendieran más a un polo antimarxista que a uno marxista" 34 .

Es decir, las fuerzas armadas, acostumbradas a no deliberar ${ }^{35}$, habrían actuado tardíamente ${ }^{36}$ y como reacción al llamado de los civiles. En otras palabras, a juicio del autor, el golpe de Estado de septiembre de 1973 debe ser entendido como la consecuencia inevitable de la "guerra civil política", es decir, habría sido responsabilidad de los civiles, y particularmente debe ser comprendido como una consecuencia del intento de la izquierda de establecer una dictadura marxista en Chile. Por eso, no estaríamos ante una conspiración sino que ante un proceso de toma de decisión que había sido paulatino, pero sostenido. Asegura Fermandois:

La idea de que habría que "hacer algo" y que esto se parecería demasiado a un golpe no fue un proceso rápido, aunque cristalizó en los once meses que duró lo que hemos llamado la guerra civil política. Esto ya sería incontrarrestable a partir del Tancazo, aunque una mecha inicial estuvo en la reunión del 11 de abril en el Ministerio de Defensa para debatir la ENU. [...] De allí en adelante, a veces reculando, pero en general proyectándose para adelante, la avalancha seguiría su curso hasta el final. Este final fue el momento en que los que estaban decididos a tomarse el poder se pusieron a la cabeza de los oficiales. En la marina esto sucedió definitivamente entre julio y agosto. En la FACH fue en la segunda mitad de agosto con un tiempo-eje que fue el reemplazo de César Ruiz Danyau por Gustavo Leigh Guzmán en la jefatura de la institución. En el Ejército sucedió entre los días 9, 10 y 11 de septiembre en la madrugada. En Carabineros sucedió en el curso de la mañana del 11 de septiembre. ${ }^{37}$

${ }^{34}$ Ibídem, 698.

${ }^{35}$ Fermandois sostiene que las fuerzas armadas chilenas fueron apolíticas, no deliberantes, desde fines de 1932. Para el autor, los complots de la década entre 1945 y 1955 serían una excepción pues sólo involucraban al Ejército, y en éste al ibañismo (p. 653). Otra excepción lo constituiría "la presencia de inquietudes sociales al interior de las filas, expresadas principalmente entre los suboficiales y el personal de tropa", en este caso, de la Armada, concretamente en 1947 y 1961 (p. 653). Posteriormente, en 1969, el Tacnazo, que "dejó una estela de pequeñas conspiraciones de oficiales, en especial en el Ejército, para intervenir en política y 'salvar al país"” (p. 657). Demasiadas "excepciones" como para seguir insistiendo en el apoliticismo de unas fuerzas armadas no deliberantes durante el siglo XX.

${ }^{36} \mathrm{El}$ autor no recoge los indicios de una temprana infiltración militar en los grupos paramilitares de izquierda y en las organizaciones más combativas de la Unidad Popular.

${ }^{37}$ Fermandois, La revolución inconclusa, 705. 
El libro termina con el golpe de Estado y el suicidio de Allende, el cual es interpretado como una clausura al sistema político democrático del país. Dice el autor en el capítulo dedicado a éste:
Allende, al escoger la muerte que tuvo, parece que quería clausu- rar los rasgos políticos tradicionales de Chile. La idea de que lo que viniera después fuera una especie de restauración democrá- tica sería imposible una vez derramada la sangre del Presidente en una batalla final. El fermento revolucionario tendría de dónde alimentarse por tiempo indefinido. ${ }^{38}$

Podemos entender por tanto que la prolongación en el tiempo de una larga dictadura militar vendría a explicarse no por el carácter de los hombres de armas que la encarnaron sino por la acción final de Allende, su decisión de quitarse la vida.

Curiosamente, el autor ha titulado su libro La revolución inconclusa, es decir, el 11 de septiembre habría dejado a la revolución socialista en la condición de "inconclusa". No es que ésta fuese derrotada o que hubiese fracasado. Queda inconclusa, nos lo explica Fermandois en el prólogo, por cuanto el proceso revolucionario iniciado bajo la Unidad Popular tenía como norte culminar en la sociedad socialista marxista, en la revolución propiamente tal. En la medida en que para el autor la revolución no concluye en el fracaso o en la derrota, el final del libro trasmite la impresión de que la revolución podría ser reactivada. Por de pronto, sostiene que "en el largo plazo de la historia contemporánea hubo un triunfo simbólico que perteneció a Salvador Allende" 39 . Ello fue así porque con su muerte

Allende podía confirmar lo que había sido un elemento esencial de su mundo de ideas y sentimientos políticos: la izquierda que encabezaba él era el único sentido de democracia que podía haber, que el proceso era irreversible, que no se podía regresar simplemente a 1970. La democracia chilena, desde esta perspectiva, era lo que iba siendo a medida que se desarrollaba, es decir, a medida que fuera personificada por el tipo de fórmula política que había representado Salvador Allende y en la medida en que hubiera un período de transición hacia la sociedad socialista tal como él y los suyos la habían visto en muchas partes del mundo. ${ }^{40}$

\footnotetext{
${ }^{38}$ Ibídem, 233.

${ }^{39}$ Ibídem, 769.

${ }^{40}$ Ibídem, 770.
} 
Tales son las líneas finales del libro. Así, si la "revolución inconclusa" termina violentamente, el libro de Fermandois termina abruptamente, y con el autor, al parecer, políticamente derrotado. Hizo falta un epílogo; hizo falta el relato sobre la enorme violencia desplegada tras el golpe de Estado y que se intentara una explicación sobre ella; hizo falta un epílogo donde se continuara la historia de esta izquierda chilena más allá del 11 de septiembre, en Chile y en el exilio, particularmente importante en la RDA y Cuba, países socialistas que a lo largo del libro tienen un relevante protagonismo. De lo contrario, el lector ha quedado con la impresión de que el autor minimiza la violencia: por de pronto destaca que en el bombardeo de La Moneda nadie murió ${ }^{41}$, y asegura que la decisión de los oficiales de sacar a Allende fuera de Chile era veraz. La voz de Pinochet incitando a que el avión fuera derribado en el mar, recogida en la grabación que Patricia Verdugo puso en conocimiento de todos, le parece a Fermandois tan sólo "comentarios de mal gusto de Pinochet"42. Sin un epílogo y con el párrafo final que hemos transcrito puede quedar la impresión de que según el autor la izquierda de los años de la Unidad Popular — para quien la democracia era sólo instrumental al logro de la sociedad socialista identificada con la dictadura del proletariado - sería fundamentalmente la misma hasta hoy.

Es cierto que el historiador debe tomar la difícil decisión de determinar cuándo concluir una historia, así como tiene que decidir cuándo comenzar. Si la crisis chilena a juicio de Fermandois se inició en la elección presidencial de 1970, habría sido conveniente comenzar allí el libro, lo que habría permitido cerrar con un epílogo sobre la violencia y el exilio, tan relevante políticamente. Habría sido una historia más breve pero más compacta y con mayores proyecciones al presente; también hubiese podido contar con un público lector mejor definido, quizás aquel lector que ha buscado Fermandois al escribir este libro, aquel que pudiese hacer suya la interpretación sobre el período que porta esta obra, crítica de la izquierda, de Allende, del gobierno de la Unidad Popular, y particularmente cercana a las sensibilidades y la racionalidad que caracteriza la visión de mundo de las fuerzas armadas. EP

\footnotetext{
${ }^{41}$ Ibídem, 768.

${ }^{42}$ Ibídem, 765.
} 